\title{
Revisiting the Role of Infralimbic Cortex in Fear Extinction with Optogenetics
}

\author{
Fabricio H. Do-Monte, ${ }^{\star}$ Gabriela Manzano-Nieves, ${ }^{\star}$ OKelvin Quiñones-Laracuente, Liorimar Ramos-Medina, \\ and Gregory J. Quirk \\ Departments of Psychiatry and Anatomy and Neurobiology, University of Puerto Rico School of Medicine, San Juan, Puerto Rico 00936
}

\begin{abstract}
Previous rodent studies have implicated the infralimbic (IL) subregion of the medial prefrontal cortex in extinction of auditory fear conditioning. However, these studies used pharmacological inactivation or electrical stimulation techniques, which lack temporal precision and neuronal specificity. Here, we used an optogenetic approach to either activate (with channelrhodopsin) or silence (with halorhodopsin) glutamatergic IL neurons during conditioned tones delivered in one of two phases: extinction training or extinction retrieval. Activating IL neurons during extinction training reduced fear expression and strengthened extinction memory the following day. Silencing IL neurons during extinction training had no effect on within-session extinction, but impaired the retrieval of extinction the following day, indicating that IL activity during extinction tones is necessary for the formation of extinction memory. Surprisingly, however, silencing IL neurons optogenetically or pharmacologically during the retrieval of extinction 1 day or 1 week following extinction training had no effect. Our findings suggest that IL activity during extinction training likely facilitates storage of extinction in target structures, but contrary to current models, IL activity does not appear to be necessary for retrieval of extinction memory.
\end{abstract}

Key words: amygdala; anxiety disorders; fear conditioning; memory; prefrontal cortex; retrieval

\section{Introduction}

More than a decade of research suggests that the infralimbic (IL) subregion of the medial prefrontal cortex is necessary for the retrieval of extinction of auditory fear conditioning in rodents (for reviews, see Sotres-Bayon et al., 2004; Milad and Quirk, 2012; Orsini and Maren, 2012; Duvarci and Pare, 2014). Lesioning or inactivating IL during extinction training has little effect on extinction within the session, but leads to impaired retrieval of extinction the following day (Quirk et al., 2000; Laurent and Westbrook, 2009; Chang and Maren, 2010; Fontanez-Nuin et al., 2011; Sierra-Mercado et al., 2011; Santini et al., 2012), implicating extinction-induced IL activity in the formation of extinction memory. Pharmacological inactivation, however, lacks the temporal precision needed to evaluate the necessity of tone-induced activity for subsequent retrieval. Electrical stimulation of IL during extinction tones facilitates the retrieval of extinction the following day (Milad et al., 2004; Vidal-Gonzalez et al., 2006; Kim et

Received July 29, 2014; revised Jan. 14, 2015; accepted Jan. 21, 2015.

Author contributions: F.H.D.-M. and G.J.Q. designed research; F.H.D.-M., G.M.-N., K.Q.-L., and L.R.-M. performed research; F.H.D.-M., G.M.-N., K.Q.-L., and L.R.-M. analyzed data; F.H.D.-M. and G.J.Q. wrote the paper.

This study was supported by National Institutes of Health grants (R37-MH058883, R01-MH081975, and P50MH086400 to G.J.Q.) and the University of Puerto Rico President's Office and support of G.M.-N. and K.Q.-L. by the UPR-RISE Program (R25-GM061151 and R25-GM061838), respectively. We thank Karl Deisseroth for viral constructs, the University of North Carolina Vector Core Facility for viral packaging, and A. C. Felix-Ortiz for technical advice.

*F.H.D.-M. and G.M.-N. contributed equally to this work.

The authors declare no competing financial interests.

Correspondence should be addressed to Fabricio H. Do-Monte, PhD, Departments of Psychiatry and Anatomy and Neurobiology, University of Puerto Rico School of Medicine, P.0. Box 365067, San Juan, Puerto Rico 00936. E-mail: fabriciodomonte@gmail.com.

DOI:10.1523/JNEUROSCI.3137-14.2015

Copyright $\odot 2015$ the authors $\quad 0270-6474 / 15 / 353607-09 \$ 15.00 / 0$ al., 2010; Maroun et al., 2012), but electrical stimulation activates fibers of passage, which may be responsible for the behavioral effects (Hamani et al., 2010).

Furthermore, it is not yet known the extent to which IL activity during retrieval tones is necessary for retrieval of extinction. Unit recording and immunocytochemical data show that increased neuronal activity in IL correlates with extinction retrieval (Milad and Quirk, 2002; Holmes et al., 2012; Knapska et al., 2012; but see Fitzgerald et al., 2014), consistent with IL-mediating retrieval. Previous studies have suggested that during extinction retrieval, IL activates intercalated GABAergic cells (ITCs) in the amygdala, which are known to inhibit central nucleus output neurons (Royer and Paré, 2002; Quirk et al., 2003; Likhtik et al., 2008; Amir et al., 2011). Surprisingly, however, no prior studies of auditory fear conditioning have manipulated IL activity during retrieval tones, leaving untested the hypothesis that IL activity is necessary for retrieval of extinction. To address these issues, we revisited the role of IL in fear extinction using an optogenetic approach to activate (channelrhodopsin) or silence (halorhodopsin) IL neurons during the tones of extinction training or extinction retrieval.

\section{Materials and Methods}

Animals. One hundred eighty-nine male Sprague Dawley rats (Harlan Laboratories) weighing 300-400 g were individually housed and handled as previously described (Quirk et al., 2000). All procedures were approved by the Institutional Animal Care and Use Committee of the University of Puerto Rico School of Medicine in compliance with the National Institutes of Health guidelines for the care and use of laboratory animals.

Surgeries. Rats were positioned in a stereotaxic frame and anesthetized with isoflurane $(2-5 \%)$ delivered through a facemask. For optogenetic 
experiments, bilateral cannulas (9 $\mathrm{mm}$ length, 22 gauge; Plastics One) were initially implanted in IL (AP: $+2.8 \mathrm{~mm}$ to bregma; ML: $\pm 0.6 \mathrm{~mm}$; DV: $-4.0 \mathrm{~mm}$; Paxinos and Watson, 1997). A $10 \mathrm{~mm}$ injector was placed inside each cannula and a pump bilaterally infused $0.5 \mu \mathrm{l}$ of one of the subsequently indicated viruses. Rats were allowed 4-6 weeks for recovery and viral expression. Rats were re-anesthetized, the injectors were removed, and a double optic fiber $(0.22 \mathrm{NA}, 200 \mu \mathrm{m}$ core; $10 \mathrm{~mm}$ length; Doric Lenses) was inserted into the guide cannulas and fixed to the skull with acrylic cement. For IL-muscimol experiments, bilateral cannulas (10 mm length, 26 gauge) were aimed at IL using an angled approach (AP: $+2.8 \mathrm{~mm}$ to bregma; ML: $\pm 3.1 \mathrm{~mm}$; DV: $-3.8 \mathrm{~mm}$; angled at $30^{\circ}$ ) to minimize drug backflow to adjacent areas (Sierra-Mercado et al., 2011).

Drugs. Infusion of fluorescently labeled muscimol (MUS; BODIPY TMR-X conjugated; Sigma-Aldrich) was used to enhance $\mathrm{GABA}_{\mathrm{A}}$ receptor activity, thereby inactivating the target structure. We used a dose of $0.11 \mathrm{nmol} / 0.2 \mu \mathrm{l} / \mathrm{side}$, similar to our previous study (Sierra-Mercado et al., 2011).

Viruses. The adeno-associated viruses (AAVs; serotype 5) were obtained from the University of North Carolina Vector Core. Viral titers were $4 \times 10^{12}$ particles/ml for AAV5:CaMKII $\alpha::$ hChR2(H134R)-EYFP, $4 \times 10^{12}$ particles/ml for AAV5:CaMKII $\alpha::$ NpHR3.0-eYFP, and $3 \times$ $10^{12}$ particles/ml for AAV5:CaMKII::eYFP. The use of a CaMKII promoter enables transgene expression favoring pyramidal neurons (Liu and Jones, 1996; Goshen et al., 2011). Viruses were housed in a $-80^{\circ} \mathrm{C}$ freezer until the day of infusion.

Laser delivery. Rats expressing channelrhodopsin (ChR2) in IL were bilaterally illuminated for $31 \mathrm{~s}$ ( $1 \mathrm{~s}$ before, $30 \mathrm{~s}$ during the tone), unless otherwise indicated, using a blue laser (473 nm DPSS laser, $5 \mathrm{~mW}, 5-50$ $\mathrm{Hz}, 5 \mathrm{~ms}$ pulse width; OEM Laser Systems; Tan et al., 2012). Rats expressing halorhodopsin (eNpHR) in IL were bilaterally illuminated for $40 \mathrm{~s}$ (10 s before, $30 \mathrm{~s}$ during the tone) using a yellow laser (593.5 nm DPSS laser, 8-10 mW, constant; OEM Laser Systems; Smith et al., 2012). Laser illumination was initiated $1 \mathrm{~s}$ (for ChR2) or $10 \mathrm{~s}$ (for eNpHR) before tone onset, given the long-response latencies observed in some IL neurons following laser illumination (see Results). Rats expressing only eYFP in IL were used to control for any nonspecific effects of viral infection or laser light. Laser light was passed through a shutter/coupler $(200 \mu \mathrm{m}$ core; Oz Optics), patchcord (200 $\mu \mathrm{m}$ core; Doric Lenses), rotary joint (200 $\mu \mathrm{m}$ core, $1 \times 2$; Doric Lenses), double patchcord (0.22 NA, $200 \mu \mathrm{m}$ core; Doric Lenses), and double optic fiber to reach the brain. Rats were familiarized with the double patchcord for at least $3 \mathrm{~d}$ before starting each behavioral session.

Fear-conditioning test. Rats underwent bar press training, auditory fear conditioning, and fear extinction in standard operant chambers (Coulbourn Instruments), inside sound-attenuating boxes (Med Associates). On day 1 (conditioning), rats were habituated to five nonreinforced tones $(75 \mathrm{~dB}, 30 \mathrm{~s}$; habituation) followed by seven tones that coterminated with a footshock $(0.5 \mathrm{~s}, 0.50 \mathrm{~mA})$. On day 2, rats were given 4-20 tones in the absence of footshock, according to each experiment. On day 3 , rats were given four tones in the absence of footshock to test for extinction retrieval. Laser illumination occurred at various time points around the tone presentation, according to each experiment. For inactivation experiments, muscimol was infused in IL $30 \mathrm{~min}$ before the extinction retrieval session on day 3 .

Unit recording. Rats expressing $\mathrm{ChR} 2$ or eNpHR in IL were anesthetized with urethane $(1 \mathrm{~g} / \mathrm{kg}$; i.p.) and positioned in a stereotaxic frame. An optrode (NB Labs) consisting of an optical fiber surrounded by six wires for recording was implanted into IL. Extracellular waveforms were amplified, digitized, and stored onto disk for further off-line analysis (Plexon), as previously described (Burgos-Robles et al., 2007). Waveforms were recorded during $10 \mathrm{~s}$ with laser off, followed by $10-31 \mathrm{~s}$ with laser on $(5-10 \mathrm{~mW})$, for various train cycles.

Histology and immunocytochemistry. Rats were transcardially perfused and brains were processed for histology as previously described (DoMonte et al., 2013). Only rats with optical fibers and viral expression (or drug infusion) located exclusively in IL were included in the statistical analysis. For cFos immunocytochemistry, rats were perfused $1 \mathrm{~h}$ after receiving blue laser illumination in the home cages (two trains of $30 \mathrm{~s}, 3$ min apart, $5 \mathrm{~mW}$, at $5 \mathrm{~Hz}$ or $20 \mathrm{~Hz}$ ). Brains were processed with anti-cFos serum raised in rabbit (1:20,000; Ab-5; Oncogene Science), as previously described (Do-Monte et al., 2013). Counts of cFos-positive neurons were performed at $20 \times$ magnification with an Olympus microscope (Model BX51) equipped with a digital camera. cFos-positive cells were automatically counted and averaged for each hemisphere at two to three distinct rostrocaudal levels of IL ( +2.7 to $+3.7 \mathrm{~mm}$ from bregma; MetaMorph software version 6.1). The density of cFos-positive neurons was calculated by dividing the number of cFos-positive neurons by the area of IL in each section.

Data collection and analysis. Behavior was recorded using digital video cameras. Freezing was hand scored by an observer blind to the experimental condition. Statistical significance was determined with paired or unpaired Student's $t$ test, repeated-measures ANOVA, or one-way ANOVA, followed by Tukey post hoc comparisons (STATISTICA6; StatSoft), as indicated for each experiment. The level of statistical significance adopted was $p<0.05$.

\section{Results}

Activating IL neurons during extinction tones reduces freezing and strengthens subsequent retrieval of extinction

Using anesthetized rats, we first assessed the effects of laserinduced activation of IL neurons expressing ChR2. Activity of IL neurons faithfully followed blue laser pulses ( $5 \mathrm{~ms}$ duration) at frequencies of $5,10,20$, and $50 \mathrm{~Hz}$ during $30 \mathrm{~s}$ of activation, with spike fidelities of $98.9 \pm 0.03,98.9 \pm 0.05,97.7 \pm 0.09$, and $88.3 \pm 0.6$, respectively (Fig. $1 A$ ). No differences were observed in the spike waveform across frequencies (Student's $t$ test; spike width: $p=0.97, t_{(56)}=0.03$; amplitude: $p=0.95, t_{(56)}=-0.05$ ), suggesting that we were recording from the same neuron. Of 64 neurons recorded in IL, $72 \%$ showed a significant increase $(n=$ $46), 2 \%$ showed a significant decrease $(n=1)$, and $26 \%$ showed no change $(n=17)$ in firing rate during laser illumination at 20 $\mathrm{Hz}$ (basal firing $=1.2 \mathrm{~Hz}$; all $p s<0.05$; Fig. $1 B$ ). Similar to the example shown in Figure $1 B, 22$ of 29 neurons maintained their firing rate throughout $31 \mathrm{~s}$ of illumination (at $20 \mathrm{~Hz}$ ), with no significant changes in response latency from the beginning to the end of the train (all ps $>0.24$ ). The average latency of IL activation was $6.1 \pm 1.9 \mathrm{~ms}$, ranging from 1 to $22 \mathrm{~ms}$ (Fig. 1B). Illumination of IL at $20 \mathrm{~Hz}$, but not $5 \mathrm{~Hz}$, significantly increased the expression of cFos in IL, compared with eYFP controls, as shown in Figure $1 C$ (one-way ANOVA followed by Tukey post hoc test; $F_{(2,13)}=16.58, p<0.001 ; 20 \mathrm{~Hz}: p<0.001, n=3 ; 5 \mathrm{~Hz}: p=0.55$, $n=6)$.

A separate set of rats was used to assess the effects of IL illumination on conditioned freezing responses. One day after conditioning, ChR2 activation of IL neurons during the tone significantly reduced freezing, as illustrated in Figure $1 D$. Repeated-measures ANOVA revealed an interaction between group and trial block $\left(F_{(3,14)}=\right.$ 11.13, $p<0.001$ ), with post hoc tests confirming a significant reduction in freezing with $\mathrm{ChR} 2$ activation at frequencies of 10 , 20 , and $50 \mathrm{~Hz}$ (all $p s<0.001)$, but not at $5 \mathrm{~Hz}(p=0.99)$. We next varied the duration of laser activation within the $30 \mathrm{~s}$ tone, from $0-5 \mathrm{~s}$ to $0-30 \mathrm{~s}$. Whereas $30 \mathrm{~s}$ of activation reduced freezing, $5 \mathrm{~s}$ of activation had no effect (Fig. 1E). Repeatedmeasures ANOVA revealed an interaction between group and trial block $\left(F_{(1,5)}=27.09, p<0.005\right)$, with post hoc tests confirming a significant reduction with $0-30 \mathrm{~s}(p=0.003)$, but not $0-5$ s activation $(p=0.99)$.

We next determined the effect of IL neuronal activation on extinction of conditioned fear. A partial extinction protocol was used, so that any reduction in freezing could be observed. Replicating our findings above, activation of IL neurons during extinction training reduced conditioned freezing (Fig. $2 A, B)$. Repeated-measures ANOVA revealed an interaction be- 
A Virus expression Optical fiber
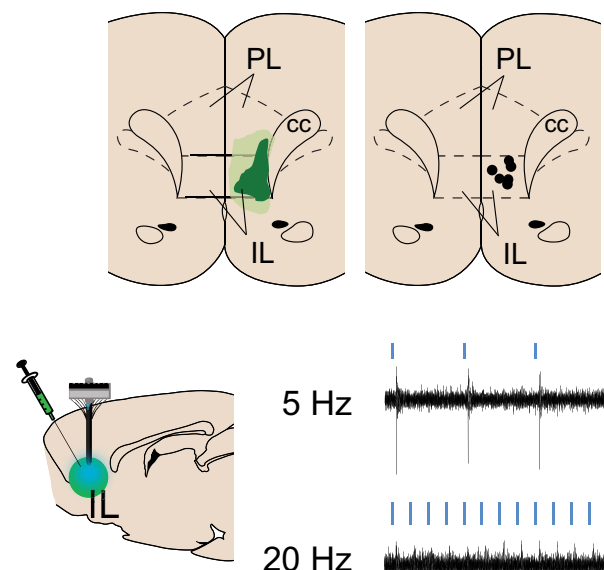

$5 \mathrm{~Hz}$

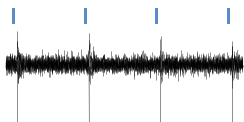

|||||||||||| $\mid$

$20 \mathrm{~Hz}$

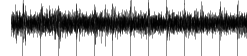

$-0.1 \mathrm{~s}$
B

$\Delta$ in IL Rate ( $n=64$ neurons)
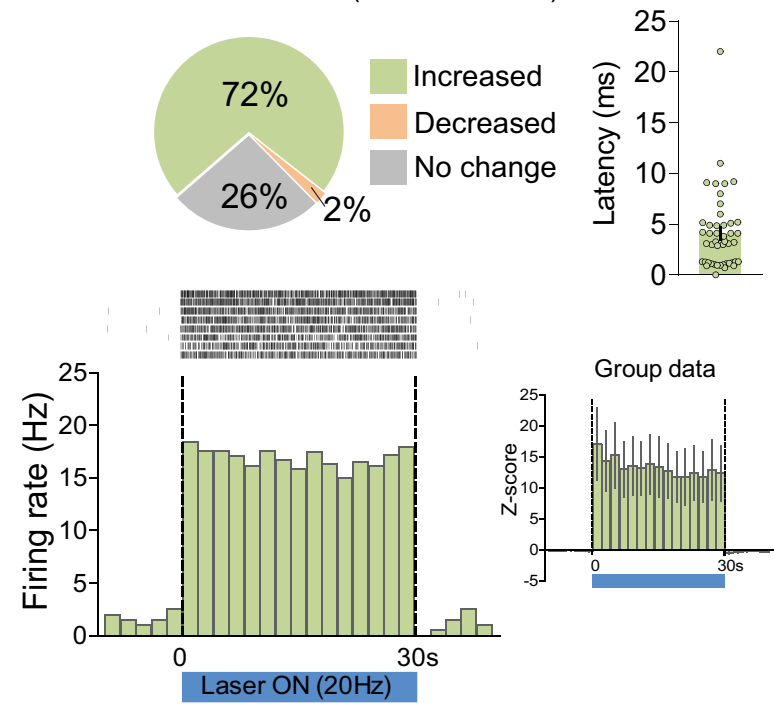

C

ChR2-eYFP

cFos - Laser $(2 \mathrm{~Hz})$
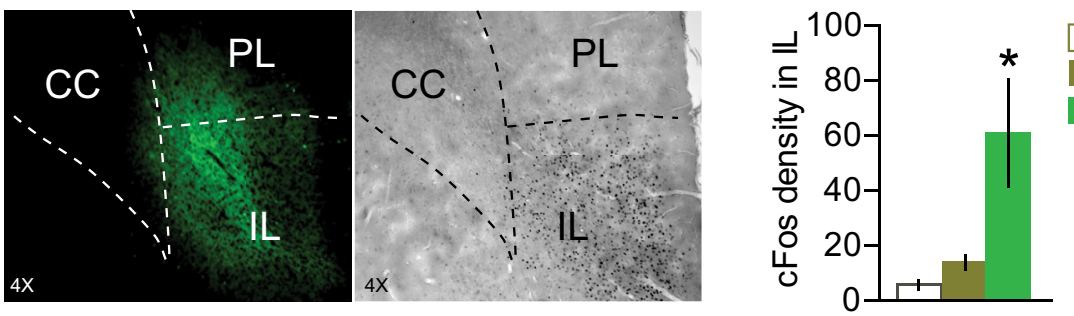

eYFP control

ChR2-eYFP $(5 \mathrm{~Hz})$

ChR2-eYFP $(20 \mathrm{~Hz})$

D

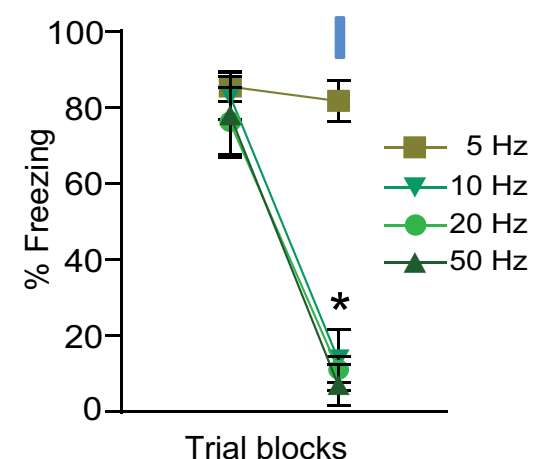

E

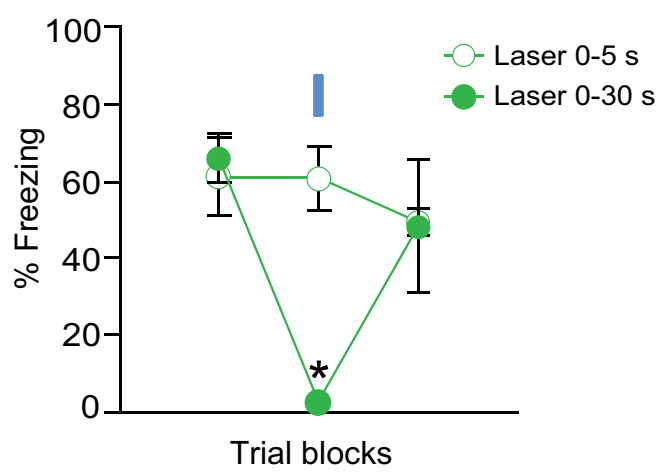

Figure 1. ChR2 activation of IL neurons reduces freezing in a frequency- and time-dependent manner. $A$, Top left, Green areas represent the minimum (darker) and the maximum (lighter) areas of ChR2 expression in IL. Top right, Black dots represent the location of optic fiber tips within IL. Bottom, Example of IL neuronal responses to ChR2 activation at 5 and $20 \mathrm{~Hz}$. B, Top left, Changes in IL firing rate with illumination of IL in rats expressing ChR2 ( $n=64$ neurons; $72 \%$ increased, $2 \%$ decreased; $26 \%$ did not change; Student's $t$ test; all ps $<0.05$ ). Top right, Latency of IL neuronal responses to laser illumination measured in bins of $1 \mathrm{~ms}$ (dots represent individual values for each neuron; bar shows average latency). Bottom left, Raster plot and peristimulus time histogram (PSTH) showing the firing rate of a representative IL neuron before, during, and after IL illumination, in a rat expressing ChR2 in IL. Bottom right, Average PSTH of IL neurons that increased their firing rate $(n=20)$ during laser illumination of IL ( $20 \mathrm{~Hz}$ during $30 \mathrm{~s}$ ). C, Left, Micrograph showing the expression of ChR2 and cFos within IL. Right, Blue laser illumination of IL at $20 \mathrm{~Hz}$, but not $5 \mathrm{~Hz}$, increased cFos density in IL, compared with eYFP control rats $\left(n=3-7\right.$ per group, one-way ANOVA, $\left.F_{(2,13)}=16.58, p<0.001\right)$. $D$, ChR2 activation with illumination of IL at frequencies of 10,20 , and $50 \mathrm{~Hz}$ (but not $5 \mathrm{~Hz}$ ) reduced freezing compared with laser-off trials $(n=4-6$ per group). $E$, ChR2 activation with illumination of IL for $0-30 \mathrm{~s}$, but not $0-5 \mathrm{~s}$, after tone onset reduced freezing compared with laser-off trials $(n=4)$. Data are shown as mean \pm SEM in blocks of two trials; ${ }^{*} p<0.05$. Blue bar indicates laser illumination. PL, prelimbic cortex; IL, infralimbic cortex; $C$, corpus callosum.

tween group and trial block $\left(F_{(3,54)}=3.87, p=0.014\right)$ during the extinction session on day 2 , with post hoc tests confirming a significant reduction in freezing in the ChR2 group in all blocks (all ps $<0.05)$. The following day, with the laser off, ChR2-activated rats continued to show reduced freezing, indicating a strengthening of extinction memory. Repeated-measures ANOVA revealed a main effect of group $\left(F_{(1,18)}=7.84, p<0.011\right)$, with post hoc tests confirming a reduction in freezing in both trial blocks (all ps $<0.05)$.

We then assessed the effect of IL neuronal activation during retrieval of extinction. A new group of rats was fear conditioned on day 1 , partially extinguished on day 2 , and tested for extinction 
A
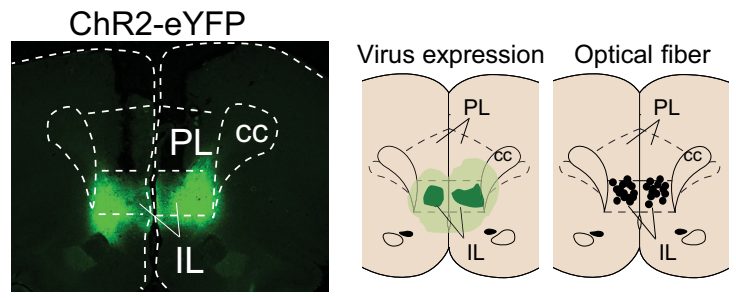

B

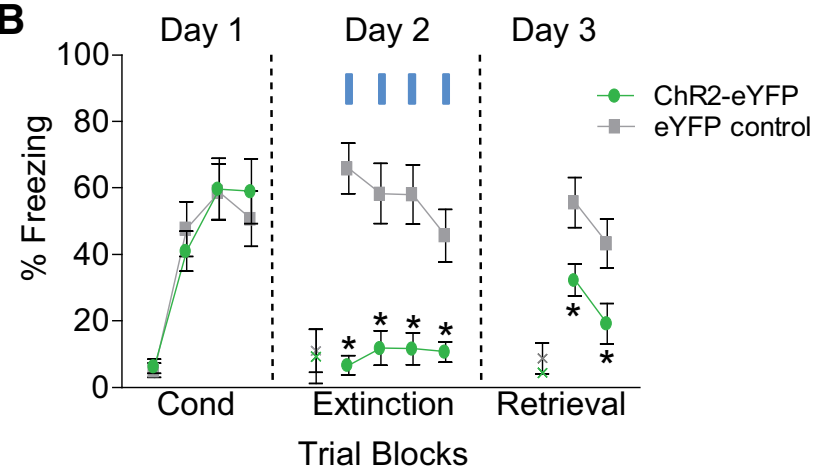

C

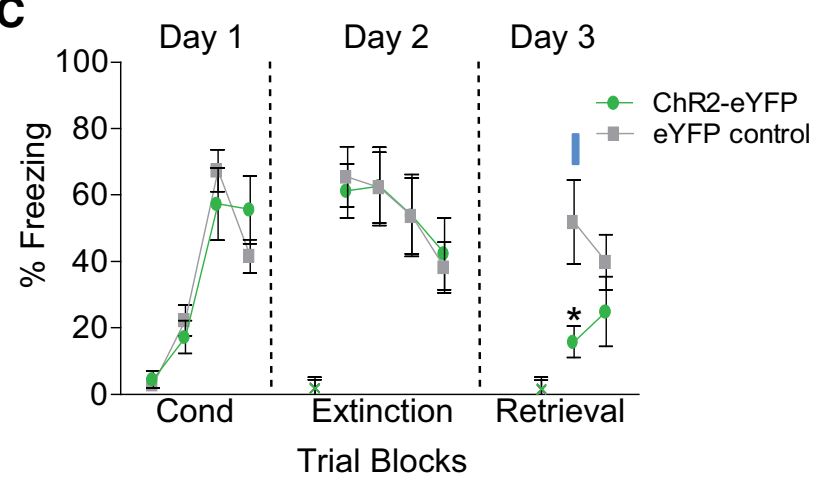

$D_{1}$

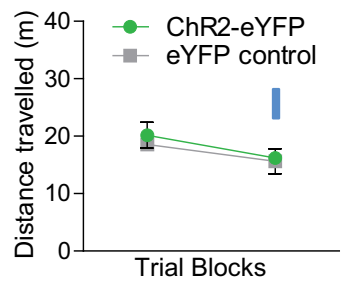

$D_{2}$

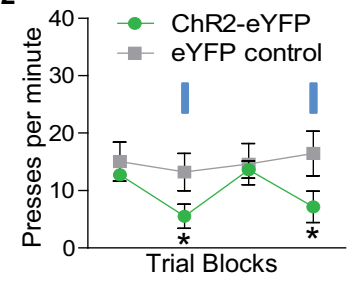

Figure 2. ChR2 activation of IL neurons facilitates subsequent retrieval of extinction. $A$, Left, Micrograph showing the expression of (hR2 within IL. Middle, Green areas represent the minimum (darker) and the maximum (lighter) areas of ChR2 expression in IL. Right, Black dots represent the location of optic fiber tips within IL. B, ChR2 activation of IL (at $20 \mathrm{~Hz}$ ) during extinction training reduced expression of freezing and facilitated extinction retrieval the following day, compared with eYFP controls ( $n=10$ per group). C, ChR2 activation of IL neurons in the first trial block of extinction retrieval (Day 3) facilitated retrieval $(p=0.04)$. $\boldsymbol{D}_{1}$, ChR2 activation of IL did not alter locomotion in an open-field task ( $n=6$ per group, 3 min laser off vs on). $\boldsymbol{D}_{2}$, ChR2 activation of IL reduced the rate of spontaneous bar pressing for food ( $n=6-7$ per group; 5 min laser off vs 5 min laser on, 2 trials). Data are shown as mean \pm SEM in blocks of two trials; ${ }^{*} p<0.05$. Blue bar, laser illumination. PL, prelimbic cortex; IL, infralimbic cortex; cc, corpus callosum; Cond, conditioning; $x$, baseline (pretone) freezing levels.

retrieval on day 3 with IL illumination. Activation of IL neurons in the first trial block reduced freezing $\left(p=0.04, t_{(9)}=2.30\right.$; Fig. $2 C)$. IL activation during the conditioned tone had no effect on rats' average velocity (pre-illumination period $=4.0 \pm 0.72 \mathrm{~cm} / \mathrm{s}$, $n=10$; illumination period $=4.6 \pm 0.8 \mathrm{~cm} / \mathrm{s}, n=10 ; p=0.47$, $\left.t_{(18)}=0.73\right)$, suggesting that illumination did not induce escape behavior in response to the conditioned stimulus. Activation of IL neurons had no effect on locomotion, as evidenced by the distance traveled in an open field during IL illumination $\left(F_{(1,11)}=1.35, p=\right.$ 0.26; Fig. $2 D_{1}$ ). However, activation of IL reduced food seeking as indicated by a significant decrease in the rate of bar pressing for food $\left(F_{(3,33)}=6.12, p=0.019\right.$; Fig. $\left.2 D_{2}\right)$, in agreement with a recent study (Richard and Berridge, 2013). Thus, the effects of ChR2 activation of IL neurons resembled previously reported effects of IL electrical stimulation: reduction in the expression of freezing and facilitation of extinction memory.

\section{Silencing IL neurons during extinction tones impairs subsequent retrieval of extinction}

In anesthetized rats, we first assessed the ability of a yellow laser to reduce activity of IL neurons expressing eNpHR (Fig. 3A). Of 17 neurons recorded in IL, $47 \%$ showed a significant decrease $(n=$ $8), 17 \%$ showed a significant increase $(n=3)$, and $36 \%$ showed no change $(n=6)$ in firing rate during laser illumination (basal firing $=3.0 \mathrm{~Hz}$; all $p$ s $<0.05$; Fig. $3 B$ ). The average latency of IL responses (both inhibitory and excitatory) was $0.61 \pm 0.28 \mathrm{~s}$ (ranging from 0.1 to $2.2 \mathrm{~s}$; Fig. $3 B$ ).

In a separate group of conditioned rats, silencing IL neurons during extinction tones had no effect on expression of conditioned freezing, or within-session extinction (Fig. 3C). Repeated-measures ANOVA during extinction training revealed a significant effect of trial block $\left(F_{(9,99)}=9.24, p<0.001\right)$, but not group $\left(F_{(1,11)}=\right.$ $0.52, p=0.48)$. On the following day, however, retrieval of extinction was impaired in rats that received IL silencing the previous day. Repeated-measures ANOVA revealed a significant effect of group $\left(F_{(1,11)}=14.50, p=0.002\right)$, with post hoc tests showing higher freezing in the eNpHR group in both trial blocks (all $p s<$ 0.05). Thus, silencing IL neurons during extinction tones impaired subsequent retrieval of extinction. Silencing IL neurons did not affect locomotion (Fig. $3 D_{1} ; F_{(1,11)}=1.24, p=0.28$ ) or food-seeking behavior (Fig. $3 D_{2} ; F_{(3,45)}=0.57, p=0.63$ ).

\section{Silencing IL neurons during retrieval tones does not impair retrieval of extinction}

Last, we assessed whether neuronal activity in IL is necessary for retrieval of extinction, by silencing IL neurons during retrieval tones. Surprisingly, silencing IL neurons at this time point did not impair retrieval of extinction learned the previous day (Fig. 4A, B; effect of group: $\left.F_{(1,24)}=0.45, p=0.50\right)$. Freezing levels during the first retrieval trial (day 3 ) did not differ between groups $(\mathrm{eNpHR}=37.7 \%, n=15$; control $=48.0 \%, n=11 ; p=0.40)$. To determine whether IL is necessary for retrieval of an older extinction memory, a subgroup of rats was given an additional retrieval test on day 10 . Silencing IL neurons at this time point also did not impair retrieval of extinction (Fig. $4 C$; effect of group: $F_{(1,11)}=0.24, p=0.62 ; \mathrm{eNpHR}=43.5 \%, n=7$; control $=$ $36.6 \%, n=6)$.

One possible explanation for the lack of effect on retrieval with IL silencing could be the short duration of silencing (40 s). To address if a longer duration of optical silencing might impair extinction retrieval, we illuminated IL for $30 \mathrm{~min}$ in these same animals (15 min before and $15 \mathrm{~min}$ during the two-tone extinction retrieval test, day 11). Similar to muscimol, silencing of IL for this duration did not impair extinction retrieval $(\mathrm{eNpHR}=$ 9.5\%, $n=7$; control $\left.=5.5 \%, n=6 ; p=0.42, t_{(11)}=0.82\right)$.

Because the virus we used (AAV5:CaMKII $\alpha:$ eNpHR3.0-eYFP) preferentially silences glutamatergic neurons (Van den Oever et al., 2013), it would spare any inhibitory neurons that could contribute to retrieval of extinction (Bissonette et al., 2014). We 
A

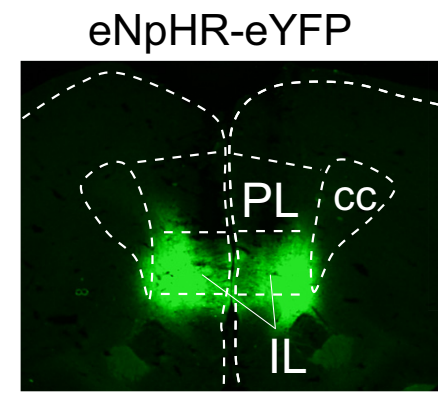

Virus expression Optical fiber
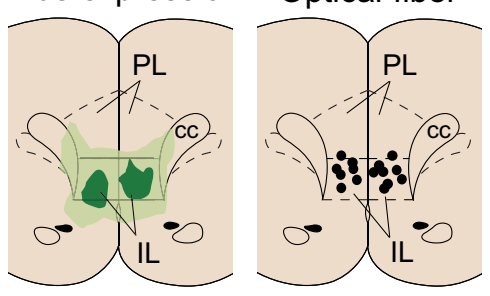

C

B

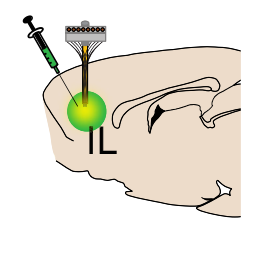

$\Delta$ in IL Rate ( $n=17$ neurons $)$
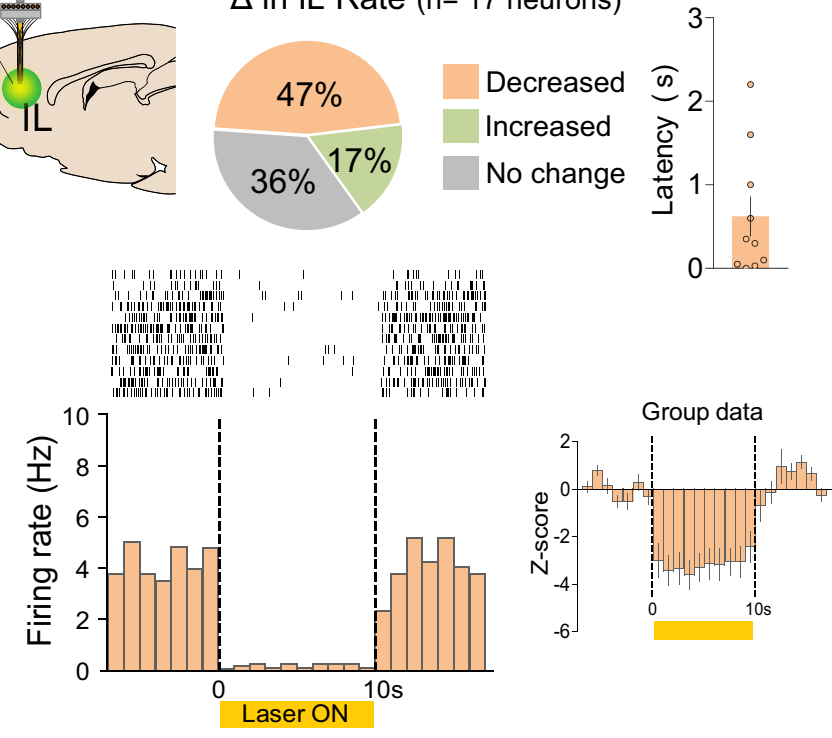

Day 2

Day3

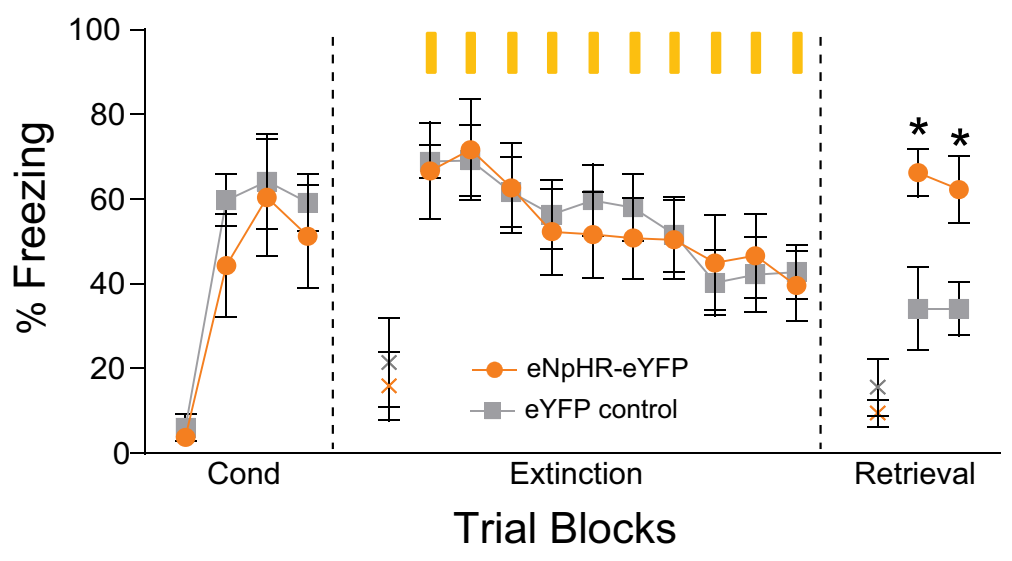

D1

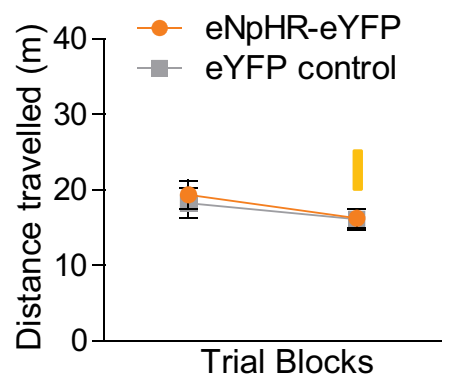

$\mathrm{D}_{2}$

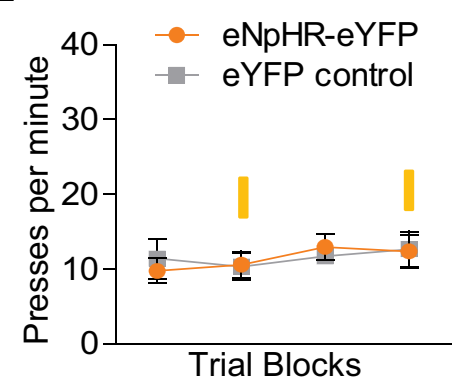

Figure 3. eNpHR silencing of IL neurons during extinction training impairs subsequent retrieval of extinction. $A$, Top, Coronal micrograph showing the expression of eNpHR within IL. Bottom left, Green areas represent the minimum (darker) and the maximum (lighter) expression of eNpHR in IL. Bottom right, Black dots represent the location of optic fiber tips within IL. $\boldsymbol{B}$, Top left, Changes in IL firing rate with illumination of IL in rats expressing eNpHR ( $n=17$ neurons; $47 \%$ decreased, $17 \%$ increased; $36 \%$ did not change; Student's t test; all $p s<0.05$ ). Top right, Latency of IL neuronal responses to laser illumination measured in bins of $100 \mathrm{~ms}$ (dots represent individual values for each neuron, bar shows average latency). Bottom left, Raster plot and peristimulus time histogram (PSTH) showing the firing rate of a representative IL neuron before, during, and after IL illumination, in a rat expressing eNpHR in IL. Bottom right, Average PSTH of IL neurons that decreased their firing rate $(n=9)$ during laser illumination of IL (10 s, constant light). C, eNpHR silencing of IL $(n=7)$ during extinction tones did not affect fear expression, but impaired retrieval of extinction the following day, compared with eYFP controls $(n=6)$. $\boldsymbol{D}_{1}$, eNpHR silencing of IL did not alter locomotion in an open-field task $\left(n=6-7\right.$ per group, 3 min laser off vs on). $\boldsymbol{D}_{2}$, eNpHR silencing of IL did not alter the rate of pressing for food ( $n=8-9$ per group; 5 min laser off vs 5 min laser on, 2 trials). Data are shown as mean \pm SEM in blocks of two; ${ }^{*} p<0.05$. Yellow bar, laser illumination. PL, prelimbic cortex; IL, infralimbic cortex; cc, corpus callosum; Cond, conditioning; $x$, baseline (pretone) freezing levels. 

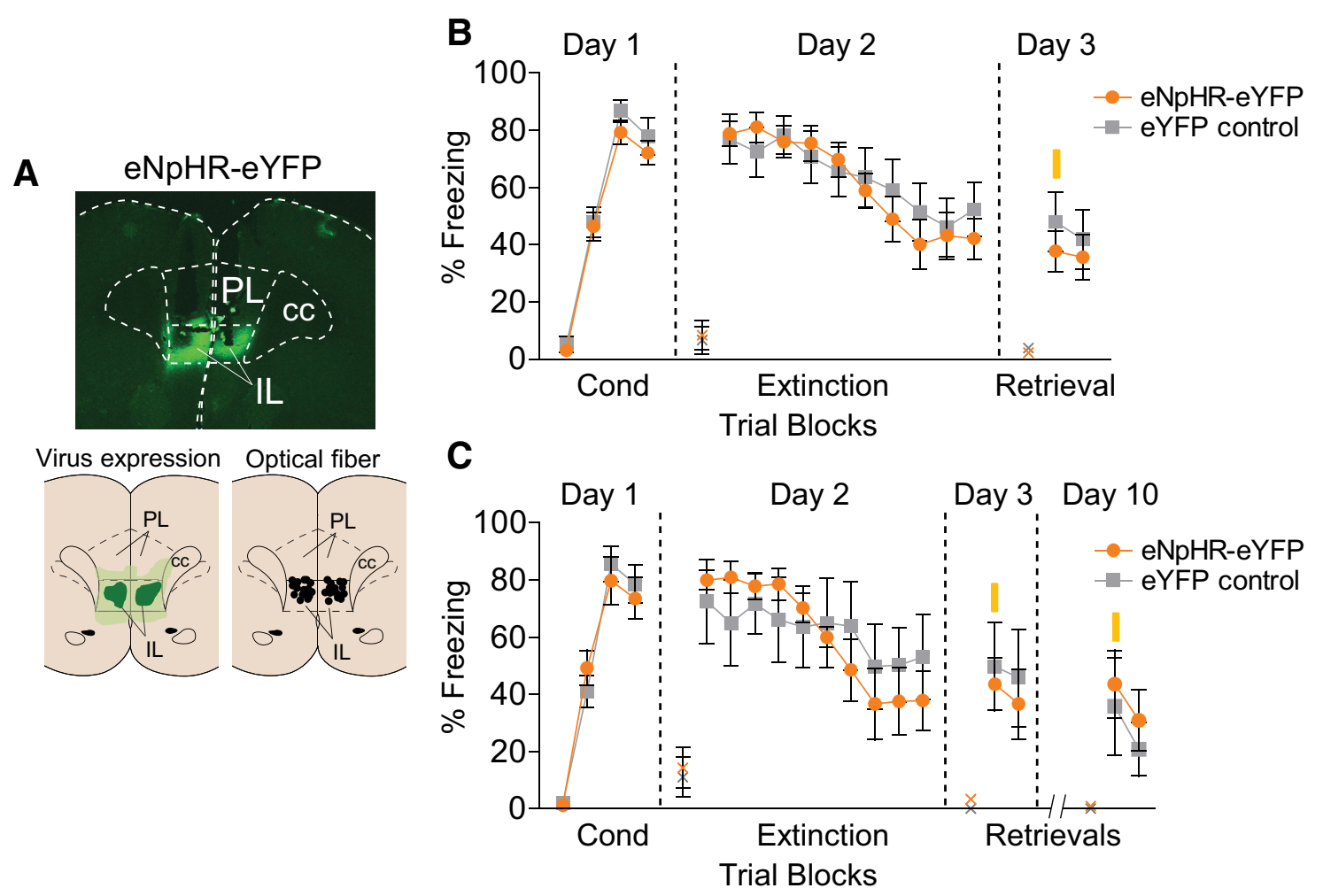

$\mathbf{E}$
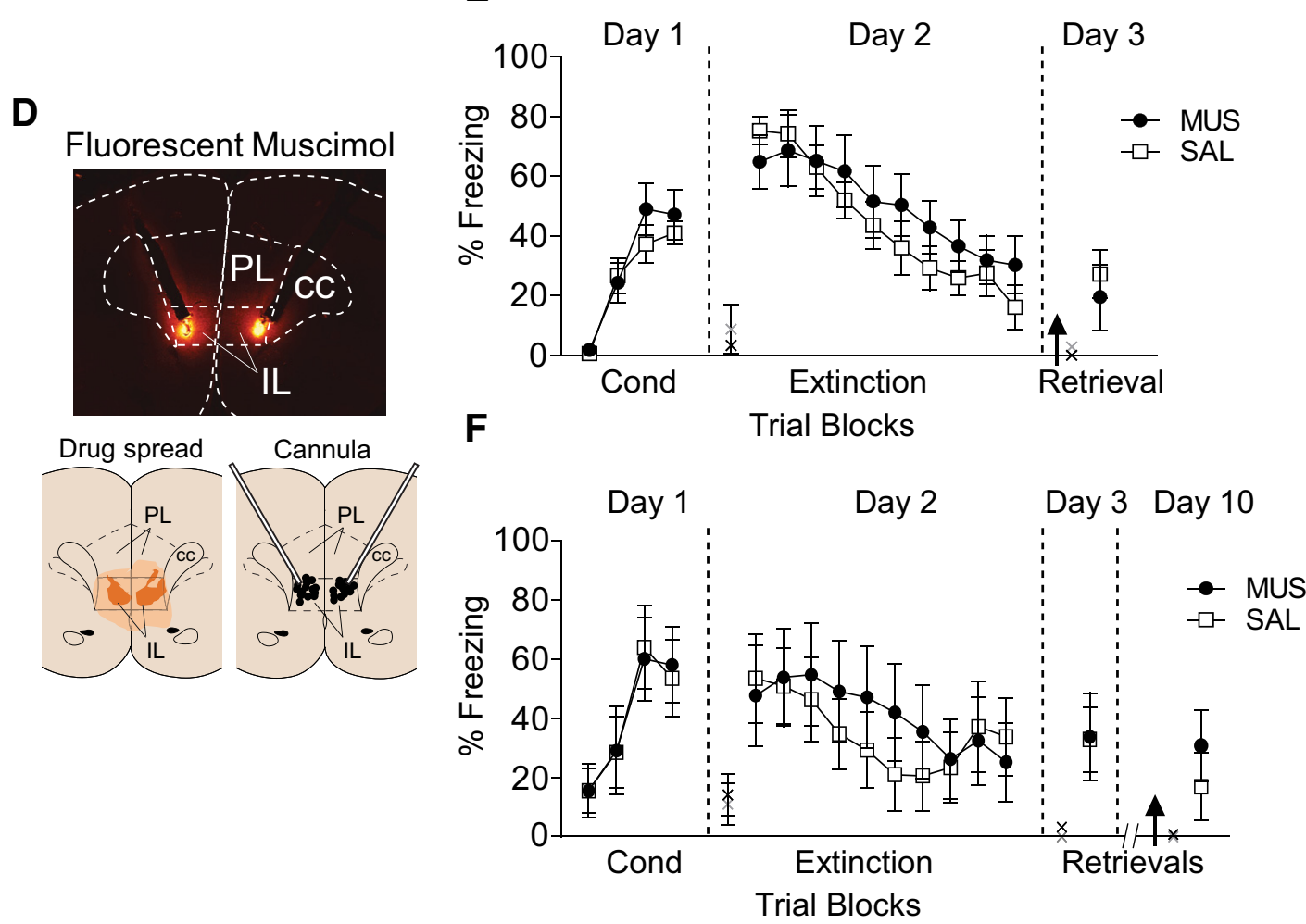

Figure 4. Silencing or inactivating IL neurons during the retrieval test does not impair retrieval of extinction. $A$, Top, Micrograph showing the expression of eNpHR within IL. Bottom left, Green areas represent the minimum (darker) and the maximum (lighter) expression of eNpHR in IL. Bottom right, Black dots represent the location of optic fiber tips within IL. B, eNpHR-YFP silencing of IL $(n=15)$ during extinction retrieval at Day 3 did not affect retrieval of extinction, compared with eYFP controls $(n=11$; Student's $t$ test, $p=0.40)$. C, In a subset of animals, illumination of eNpHR rats $(n=7)$ during an additional retrieval test on Day 10 also did not impair retrieval of extinction, compared with eYFP controls $(n=6 ;$; Student's $t$ test, $p=0.52)$. D, Top, Micrograph showing the spread of fluorescent muscimol within IL. Bottom left, Orange areas represent the minimum (darker) and the maximum (lighter) spread of MUS in IL. Bottom right, Black dots represent the location of cannula tips within IL. $E$, Muscimol inactivation of IL (black arrow; $n=10$ ) during the retrieval test on Day 3 did not impair retrieval of extinction, compared with the saline (SAL) group ( $n=10$; Student's t test, $p=0.58) . F$, In another set of rats, muscimol inactivation of IL $(n=7)$ during the retrieval test on Day 10 also did not impair retrieval of extinction, compared with the saline group $(n=8$; Student'st test, $p=0.42)$. Data are shown as mean \pm SEM in blocks of two; ${ }^{*} p<0.05$. Yellow bar, laser illumination. PL, prelimbic cortex; IL, infralimbic cortex; cc, corpus callosum; Cond, conditioning; $x$, baseline (pretone) freezing levels. 
therefore performed an additional experiment using a nonspecific pharmacological inhibition with the $\mathrm{GABA}_{\mathrm{A}}$ agonist MUS infused into IL. We used a fluorescently labeled MUS together with an angled cannula approach, to reduce spread of MUS to structures adjacent to IL (Sierra-Mercado et al., 2011; Fig. 4D). Similar to our optogenetic findings, pharmacological inactivation of IL during extinction retrieval on either day 3 or day 10 had no effect. Freezing during the retrieval trials on day 3 (Fig. $4 E$ ) or day 10 (Fig. $4 F$ ) did not differ between groups (day 3: MUS $=19.5 \%, n=10$; $\mathrm{SAL}=27.2 \%, n=10, p=0.58, t_{(18)}=0.56$; day $10: \mathrm{MUS}=30.8 \%$, $\left.n=7 ; \mathrm{SAL}=17.0 \%, n=8, p=0.42, t_{(13)}=0.83\right)$.

To confirm that the dose of fluorescent muscimol we used was sufficient to inactivate IL neurons, we performed an additional experiment in which rats were infused with MUS before extinction training. Both MUS and SAL groups showed the same levels of freezing during the conditioning session (last conditioning block: MUS $=73.6 \%, n=6$; SAL $=68.5 \%, n=8 ; p=0.66, t_{(12)}$ $=0.44$ ). Similar to our halorhodopsin findings, inactivation of IL before extinction training did not impair within-session extinction (difference in freezing between the first and the last blocks of extinction: MUS $=28.3 \%$; SAL $=30.1 \% ; p=0.94, t_{(12)}=0.06$ ), but impaired extinction retrieval the following day (freezing: MUS $=54.4 \% ;$ SAL $\left.=15.7 \% ; p=0.03, t_{(12)}=2.44\right)$. Thus, inhibition of IL activity with either optogenetic or pharmacological approaches during retrieval did not impair retrieval of extinction, indicating that IL activity is not necessary at this time point.

\section{Discussion}

Here we examined the role of the IL prefrontal cortex in the extinction of auditory conditioned fear using an optogenetic approach to activate or silence IL neurons during the tones of extinction training or extinction retrieval. Consistent with previous electrical stimulation studies, ChR2 activation of IL neurons reduced freezing and strengthened extinction memory. Consistent with previous pharmacological studies, eNpHR silencing of IL neurons left within-session extinction intact, but impaired subsequent retrieval of extinction. However, in disagreement with a popular model of IL function, eNpHR silencing or pharmacological inactivation of IL neurons during retrieval did not impair retrieval of extinction.

Our observation that ChR2 activation of IL for $31 \mathrm{~s}$ at rates of $10-50 \mathrm{~Hz}$ reduces conditioned freezing confirms previous studies using electrical stimulation (Milad and Quirk, 2002; Milad et al., 2004; Vidal-Gonzalez et al., 2006; Kim et al., 2010; Maroun et al., 2012). The lack of effect with $5 \mathrm{~Hz}$ activation agrees with a previous study using electrical stimulation of IL (Shehadi and Maroun, 2013), and may be due to the fact that $5 \mathrm{~Hz}$ approximates the spontaneous firing rate of IL neurons (Milad and Quirk, 2002; Holmes et al., 2012). ChR2 activation of IL 0-5 s after tone onset did not reduce freezing, which is somewhat surprising given that electrical stimulation of IL from 100 to $400 \mathrm{~ms}$ after tone onset attenuated freezing (Milad and Quirk, 2002; Milad et al., 2004). Unlike optogenetic stimulation, electrical stimulation activates both inhibitory neurons and fibers of passage with little control over the spread of current, which could account for the difference in effects with this timing.

In agreement with our optogenetic findings, electrical stimulation of IL during extinction training strengthens extinction retrieval the following day (Milad and Quirk, 2002; Vidal-Gonzalez et al., 2006; Kim et al., 2010; Maroun et al., 2012). Therefore, previously reported strengthening of extinction memory with electrical stimulation of IL is unlikely due to fibers of passage (Hamani et al., 2010); however, the constant interspike intervals used in previous electrical studies and our optogenetic study does not mimic naturally occurring bursting patterns in IL (BurgosRobles et al., 2007). The reduction in rates of bar pressing suggests that IL activity reduces food seeking, probably through indirect activation of the nucleus accumbens shell (Hanlon et al., 2004; Richard and Berridge, 2013).

Our observation that retrieval of extinction was impaired by silencing IL neurons during extinction training is consistent with previous pharmacological inactivation studies (Sierra-Mercado et al., 2006; Burgos-Robles et al., 2007; Fontanez-Nuin et al., 2011; Sierra-Mercado et al., 2011; Santini et al., 2012), as well as studies showing that extinction training induces plasticity in IL (Kim et al., 2011; Sepulveda-Orengo et al., 2013). Previous recording studies showed elevated tone responses of IL neurons during extinction training (Chang et al., 2010; Holmes et al., 2012, but see Milad and Quirk, 2002), and our eNpHR findings suggest that these tone responses are essential for the formation of the extinction memory.

A similar extinction role for IL has been demonstrated in extinction of contextual fear conditioning (Laurent and Westbrook, 2009; Do-Monte et al., 2010; 2013; Farrell et al., 2010; Thompson et al., 2010; Kritman and Maroun, 2013), extinction of appetitive conditioning (Rhodes and Killcross, 2004; Peters and De Vries, 2013), and extinction of drug seeking (LaLumiere et al., 2010; Van den Oever et al., 2013; Gass et al., 2014; Otis et al., 2014). Our eNpHR data indicate that IL activity is not necessary for within-session extinction of freezing, in agreement with lesion studies (Quirk et al., 2000; Lebrón et al., 2004; Chang and Maren, 2010), but not muscimol studies (Sierra-Mercado et al., 2011). Within-session extinction of freezing likely depends on activity in the BLA, as blockade of NMDA receptors in BLA impaired within-session extinction (Sotres-Bayon et al., 2007; Zimmerman and Maren, 2010), and activation of NMDA receptors in BLA facilitated within-session extinction (Baker et al., 2012).

In contrast to the importance of IL activity during extinction training, we found that IL activity during retrieval was not necessary for retrieval of extinction. Previous recording studies have shown that IL activity is correlated with retrieval of fear extinction (Milad and Quirk, 2002; Holmes et al., 2012; Knapska et al., 2012). However, no prior study tested the necessity of IL activity for the retrieval of auditory fear extinction. Why is IL activity during extinction training necessary for later retrieval, but not during retrieval itself? One possibility is that IL activity during training induces plasticity in downstream targets of IL, which would affect behavior the following day. Amygdala ITC cells constitute a likely target candidate. IL inputs exert an extremely powerful depolarizing influence on ITC cells, inducing high-frequency bursts (Amir et al., 2011). This strong depolarization may facilitate induction of NMDA-dependent plasticity at BLA inputs onto the same cells (Royer and Paré, 2002). Indeed, Amano et al. (2010) showed that $1 \mathrm{~d}$ after extinction training, BLA synapses onto ITC cells were potentiated, but this potentiation did not develop when IL was inactivated during extinction training. Thus, during subsequent retrieval, freezing would be reduced by potentiation of BLA connections to ITC, rather than IL connections to ITC (Quirk et al., 2003; Likhtik et al., 2008; Amir et al., 2011). In fact, a recent optogenetic study showed that $1 \mathrm{~d}$ after extinction training, IL synapses onto ITC cells were not potentiated (Cho et al., 2013), further supporting our observation that IL activity is not essential for retrieval of extinction.

In apparent disagreement with our findings, a prior study showed that pharmacological inactivation of IL during a retrieval test impaired retrieval of contextual fear extinction (Laurent and 
Westbrook, 2009). One possible explanation is that IL communicates contextual information for retrieval of extinction (Xu and Südhof, 2013; Zelikowsky et al., 2013), which would be less of a factor in our auditory fear-conditioning task. Pharmacological inactivation of IL also impaired retrieval of fear extinction in a paradigm requiring rats to distinguish aversive cues from safety cues (Sangha et al., 2014). Thus, in tasks involving context shifts or cue discriminations, IL may be recruited to mediate retrieval of extinction. Yet, in simple auditory fear conditioning, IL activity is only necessary during extinction training. IL may provide a "teaching signal" to downstream structures (e.g., amygdala), which facilitates the association of tones with a no-shock outcome. Such a signal may reflect the convergence of inputs to IL signaling auditory, contextual, and internal state information (Sotres-Bayon and Quirk, 2010).

Our findings are consistent with human fMRI imaging studies of fear conditioning. The human homolog of IL, ventromedial prefrontal cortex (vmPFC), increases its activity with the progression of extinction training (Phelps et al., 2004; Milad et al., 2007), together with the amygdala (Milad et al., 2007). The following day, during retrieval of extinction, vmPFC activity is correlated with extinction success (Phelps et al., 2004; Milad et al., 2007). However, the necessity of these vmPFC signals for successful extinction cannot be evaluated yet in humans. Our findings emphasize the importance of vmPFC signaling during the initial learning of extinction, rather than its subsequent retrieval.

\section{References}

Amano T, Unal CT, Paré D (2010) Synaptic correlates of fear extinction in the amygdala. Nat Neurosci 13:489-494. CrossRef Medline

Amir A, Amano T, Pare D (2011) Physiological identification and infralimbic responsiveness of rat intercalated amygdala neurons. J Neurophysiol 105:3054-3066. CrossRef Medline

Baker KD, McNally GP, Richardson R (2012) D-cycloserine does not facilitate fear extinction by reducing conditioned stimulus processing or promoting conditioned inhibition to contextual cues. Learn Mem 19:461-469. CrossRef Medline

Bissonette GB, Bae MH, Suresh T, Jaffe DE, Powell EM (2014) Prefrontal cognitive deficits in mice with altered cerebral cortical GABAergic interneurons. Behav Brain Res 259:143-151. CrossRef Medline

Burgos-Robles A, Vidal-Gonzalez I, Santini E, Quirk GJ (2007) Consolidation of fear extinction requires NMDA receptor-dependent bursting in the ventromedial prefrontal cortex. Neuron 53:871-880. CrossRef Medline

Chang CH, Maren S (2010) Strain difference in the effect of infralimbic cortex lesions on fear extinction in rats. Behav Neurosci 124:391-397. CrossRef Medline

Chang CH, Berke JD, Maren S (2010) Single-unit activity in the medial prefrontal cortex during immediate and delayed extinction of fear in rats. PLoS One 5:e11971. CrossRef Medline

Cho JH, Deisseroth K, Bolshakov VY (2013) Synaptic encoding of fear extinction in mPFC-amygdala circuits. Neuron 80:1491-1507. CrossRef Medline

Do-Monte FH, Kincheski GC, Pavesi E, Sordi R, Assreuy J, Carobrez AP (2010) Role of beta-adrenergic receptors in the ventromedial prefrontal cortex during contextual fear extinction in rats. Neurobiol Learn Mem 94:318-328. CrossRef Medline

Do-Monte FH, Rodriguez-Romaguera J, Rosas-Vidal LE, Quirk GJ (2013) Deep brain stimulation of the ventral striatum increases BDNF in the fear extinction circuit. Front Behav Neurosci 7:102. CrossRef Medline

Do Monte FH, Souza RR, Bitencourt RM, Kroon JA, Takahashi RN (2013) Infusion of cannabidiol into infralimbic cortex facilitates fear extinction via $\mathrm{CB} 1$ receptors. Behav Brain Res 250:23-27. CrossRef Medline

Duvarci S, Pare D (2014) Amygdala microcircuits controlling learned fear. Neuron 82:966-980. CrossRef Medline

Farrell MR, Sayed JA, Underwood AR, Wellman CL (2010) Lesion of infralimbic cortex occludes stress effects on retrieval of extinction but not fear conditioning. Neurobiol Learn Mem 94:240-246. CrossRef Medline

Fitzgerald PJ, Whittle N, Flynn SM, Graybeal C, Pinard CR, Gunduz-Cinar O,
Kravitz AV, Singewald N, Holmes A (2014) Prefrontal single-unit firing associated with deficient extinction in mice. Neurobiol Learn Mem 113: 69-81. CrossRef Medline

Fontanez-Nuin DE, Santini E, Quirk GJ, Porter JT (2011) Memory for fear extinction requires mGluR5-mediated activation of infralimbic neurons. Cereb Cortex 21:727-735. CrossRef Medline

Gass JT, Trantham-Davidson H, Kassab AS, Glen WB Jr, Olive MF, Chandler LJ (2014) Enhancement of extinction learning attenuates ethanolseeking behavior and alters plasticity in the prefrontal cortex. J Neurosci 34:7562-7574. CrossRef Medline

Goshen I, Brodsky M, Prakash R, Wallace J, Gradinaru V, Ramakrishnan C, Deisseroth K (2011) Dynamics of retrieval strategies for remote memories. Cell 147:678-689. CrossRef Medline

Hamani C, Diwan M, Macedo CE, Brandão ML, Shumake J, Gonzalez-Lima F, Raymond R, Lozano AM, Fletcher PJ, Nobrega JN (2010) Antidepressantlike effects of medial prefrontal cortex deep brain stimulation in rats. Biol Psychiatry 67:117-124. CrossRef Medline

Hanlon EC, Baldo BA, Sadeghian K, Kelley AE (2004) Increases in food intake or food-seeking behavior induced by GABAergic, opioid, or dopaminergic stimulation of the nucleus accumbens: is it hunger? Psychopharmacology 172:241-247. CrossRef Medline

Holmes A, Fitzgerald PJ, MacPherson KP, DeBrouse L, Colacicco G, Flynn SM, MasneufS, Pleil KE, Li C, Marcinkiewcz CA, Kash TL, Gunduz-Cinar O, Camp M (2012) Chronic alcohol remodels prefrontal neurons and disrupts NMDAR-mediated fear extinction encoding. Nat Neurosci 15: 1359-1361. CrossRef Medline

Kim JH, Li S, Richardson R (2011) Immunohistochemical analyses of longterm extinction of conditioned fear in adolescent rats. Cereb Cortex 21: 530-538. CrossRef Medline

Kim SC, Jo YS, Kim IH, Kim H, Choi JS (2010) Lack of medial prefrontal cortex activation underlies the immediate extinction deficit. J Neurosci 30:832-837. CrossRef Medline

Knapska E, Macias M, Mikosz M, Nowak A, Owczarek D, Wawrzyniak M, Pieprzyk M, Cymerman IA, Werka T, Sheng M, Maren S, Jaworski J, Kaczmarek L (2012) Functional anatomy of neural circuits regulating fear and extinction. Proc Natl Acad Sci U S A 109:17093-17098. CrossRef Medline

Kritman M, Maroun M (2013) Inhibition of the PI3 kinase cascade in corticolimbic circuit: temporal and differential effects on contextual fear and extinction. Int J Neuropsychopharmacol 16:825-833. CrossRef Medline

LaLumiere RT, Niehoff KE, Kalivas PW (2010) The infralimbic cortex regulates the consolidation of extinction after cocaine self-administration. Learn Mem 17:168-175. CrossRef Medline

Laurent V, Westbrook RF (2009) Inactivation of the infralimbic but not the prelimbic cortex impairs consolidation and retrieval of fear extinction. Learn Mem 16:520-529. CrossRef Medline

Lebrón K, Milad MR, Quirk GJ (2004) Delayed recall of fear extinction in rats with lesions of ventral medial prefrontal cortex. Learn Mem 11:544548. CrossRef Medline

Likhtik E, Popa D, Apergis-Schoute J, Fidacaro GA, Paré D (2008) Amygdala intercalated neurons are required for expression of fear extinction. Nature 454:642-645. CrossRef Medline

Liu XB, Jones EG (1996) Localization of alpha type II calcium calmodulindependent protein kinase at glutamatergic but not gamma-aminobutyric acid (GABAergic) synapses in thalamus and cerebral cortex. Proc Natl Acad Sci U S A 93:7332-7336. CrossRef Medline

Maroun M, Kavushansky A, Holmes A, Wellman C, Motanis H (2012) Enhanced extinction of aversive memories by high-frequency stimulation of the rat infralimbic cortex. PLoS One 7:e35853. CrossRef Medline

Milad MR, Quirk GJ (2002) Neurons in medial prefrontal cortex signal memory for fear extinction. Nature 420:70-74. CrossRef Medline

Milad MR, Quirk GJ (2012) Fear extinction as a model for translational neuroscience: ten years of progress. Annu Rev Psychol 63:129-151. CrossRef Medline

Milad MR, Vidal-Gonzalez I, Quirk GJ (2004) Electrical stimulation of medial prefrontal cortex reduces conditioned fear in a temporally specific manner. Behav Neurosci 118:389-394. CrossRef Medline

Milad MR, Wright CI, Orr SP, Pitman RK, Quirk GJ, Rauch SL (2007) Recall of fear extinction in humans activates the ventromedial prefrontal cortex and hippocampus in concert. Biol Psychiatry 62:446-454. CrossRef Medline

Orsini CA, Maren S (2012) Neural and cellular mechanisms of fear and 
extinction memory formation. Neurosci Biobehav Rev 36:1773-1802. CrossRef Medline

Otis JM, Fitzgerald MK, Mueller D (2014) Infralimbic BDNF/TrkB enhancement of GluN2B currents facilitates extinction of a cocaine-conditioned place preference. J Neurosci 34:6057-6064. CrossRef Medline

Paxinos G, Watson C (1997) The rat brain in stereotaxic coordinates, Ed 3. San Diego, CA: Academic.

Peters J, De Vries TJ (2013) D-cycloserine administered directly to infralimbic medial prefrontal cortex enhances extinction memory in sucroseseeking animals. Neuroscience 230:24-30. CrossRef Medline

Phelps EA, Delgado MR, Nearing KI, LeDoux JE (2004) Extinction learning in humans: role of the amygdala and vmPFC. Neuron 43:897-905. CrossRef Medline

Quirk GJ, Russo GK, Barron JL, Lebron K (2000) The role of ventromedial prefrontal cortex in the recovery of extinguished fear. J Neurosci 20:62256231. Medline

Quirk GJ, Likhtik E, Pelletier JG, Paré D (2003) Stimulation of medial prefrontal cortex decreases the responsiveness of central amygdala output neurons. J Neurosci 23:8800-8807. Medline

Rhodes SE, Killcross S (2004) Lesions of rat infralimbic cortex enhance recovery and reinstatement of an appetitive Pavlovian response. Learn Mem 11:611-616. CrossRef Medline

Richard JM, Berridge KC (2013) Prefrontal cortex modulates desire and dread generated by nucleus accumbens glutamate disruption. Biol Psychiatry 73:360-370. CrossRef Medline

Royer S, Paré D (2002) Bidirectional synaptic plasticity in intercalated amygdala neurons and the extinction of conditioned fear responses. Neuroscience 115:455-462. CrossRef Medline

Sangha S, Robinson PD, Greba Q, Davies DA, Howland JG (2014) Alterations in reward, fear and safety cue discrimination after inactivation of the rat prelimbic and infralimbic cortices. Neuropsychopharmacology 39: 2405-2413. CrossRef Medline

Santini E, Sepulveda-Orengo M, Porter JT (2012) Muscarinic receptors modulate the intrinsic excitability of infralimbic neurons and consolidation of fear extinction. Neuropsychopharmacology 37:2047-2056. CrossRef Medline

Sepulveda-Orengo MT, Lopez AV, Soler-Cedeño O, Porter JT (2013) Fear extinction induces mGluR5-mediated synaptic and intrinsic plasticity in infralimbic neurons. J Neurosci 33:7184-7193. CrossRef Medline

Shehadi K, Maroun M (2013) Different effects of low frequency stimulation to infralimbic prefrontal cortex on extinction of aversive memories. Brain Res 1490:111-116. CrossRef Medline

Sierra-Mercado D, Padilla-Coreano N, Quirk GJ (2011) Dissociable roles of prelimbic and infralimbic cortices, ventral hippocampus, and basolateral amygdala in the expression and extinction of conditioned fear. Neuropsychopharmacology 36:529-538. CrossRef Medline

Sierra-Mercado D Jr, Corcoran KA, Lebrón-Milad K, Quirk GJ (2006) Inactivation of the ventromedial prefrontal cortex reduces expression of conditioned fear and impairs subsequent recall of extinction. Eur J Neurosci 24:1751-1758. CrossRef Medline

Smith KS, Virkud A, Deisseroth K, Graybiel AM (2012) Reversible online control of habitual behavior by optogenetic perturbation of medial prefrontal cortex. Proc Natl Acad Sci U S A 109:18932-18937. CrossRef Medline

Sotres-Bayon F, Quirk GJ (2010) Prefrontal control of fear: more than just extinction. Curr Opin Neurobiol 20:231-235. CrossRef Medline

Sotres-Bayon F, Bush DE, LeDoux JE (2004) Emotional perseveration: an update on prefrontal-amygdala interactions in fear extinction. Learn Mem 11:525-535. CrossRef Medline

Sotres-Bayon F, Bush DE, LeDoux JE (2007) Acquisition of fear extinction requires activation of NR2B-containing NMDA receptors in the lateral amygdala. Neuropsychopharmacology 32:1929-1940. CrossRef Medline

Tan KR, Yvon C, Turiault M, Mirzabekov JJ, Doehner J, Labouèbe G, Deisseroth K, Tye KM, Lüscher C (2012) GABA neurons of the VTA drive conditioned place aversion. Neuron 73:1173-1183. CrossRef Medline

Thompson BM, Baratta MV, Biedenkapp JC, Rudy JW, Watkins LR, Maier SF (2010) Activation of the infralimbic cortex in a fear context enhances extinction learning. Learn Mem 17:591-599. CrossRef Medline

Van den Oever MC, Rotaru DC, Heinsbroek JA, Gouwenberg Y, Deisseroth K, Stuber GD, Mansvelder HD, Smit AB (2013) Ventromedial prefrontal cortex pyramidal cells have a temporal dynamic role in recall and extinction of cocaine-associated memory. J Neurosci 33:18225-18233. CrossRef Medline

Vidal-Gonzalez I, Vidal-Gonzalez B, Rauch SL, Quirk GJ (2006) Microstimulation reveals opposing influences of prelimbic and infralimbic cortex on the expression of conditioned fear. Learn Mem 13:728-733. CrossRef Medline

Xu W, Südhof TC (2013) A neural circuit for memory specificity and generalization. Science 339:1290-1295. CrossRef Medline

Zelikowsky M, Bissiere S, Hast TA, Bennett RZ, Abdipranoto A, Vissel B, Fanselow MS (2013) Prefrontal microcircuit underlies contextual learning after hippocampal loss. Proc Natl Acad Sci U S A 110:9938-9943. CrossRef Medline

Zimmerman JM, Maren S (2010) NMDA receptor antagonism in the basolateral but not central amygdala blocks the extinction of Pavlovian fear conditioning in rats. Eur J Neurosci 31:1664-1670. CrossRef Medline 